\title{
Venous Sinus Thrombosis Following Repair of Compound Depressed Fractures Overlying Sinuses
}

\author{
AHMED A. ABD ELKHALEK, M.D. and MOHAMED A. THABIT, M.D. \\ The Department of Neurosurgery, Faculty of Medicine, Cairo University
}

\begin{abstract}
Background: Traumatic dural venous sinus injury associated with depressed skull fracture is one of the most dangerous complications of traumatic brain injury, because it may be complicated during repair by fatal venous bleeding or postoperatively with venous sinus thrombosis.
\end{abstract}

Aim of Study: In this research we will evaluate the incidence and management of venous sinus thrombosis following repair of cases of traumatic compound depressed skull fractures overlying venous sinuses.

Patients and Methods: This is a retrospective study of 40 cases of compound depressed fractures overlying dural venous sinuses, operated in the period between May 2015 to May 2016 , all cases subjected to surgery for elevation of depressed skull fracture, follow-up ranged from 3 to 6 months.

Results: In 22 cases (55\%) the bleeding was controlled by direct gelfoam compression, in 10 cases $(25 \%)$ the bleeding was controlled by direct stitching of the dural tear followed by gelfoam compression, in 6 cases $(15 \%)$ the bleeding was controlled by pericranium duroplasty, 2 cases $(5 \%)$ bleeding was controlled by free muscle duroplasty.

Two cases (5\%) developed complete obstruction of the venous sinus, the 2 cases were operated by pericranium duroplasty, both were early managed with anticoagulants, one of them later in the follow-up developed benign intracranial hypertension.

Conclusion: Venous sinus thrombosis uncommonly occur after repair of compound depressed skull fractures overlying venous sinuses, early management with anticoagulation will result in good outcome, thrombi in sinuses frequently recanalize with time due to fibrinolysis.

Key Words: Sinus thrombosis - Depressed fracture - Anticoagulants.

\section{Introduction}

SKULL fractures are classified into linear, depressed (simple or compound) and comminuted, depressed skull fractures account for $6 \%$ of head

Correspondence to: Dr. Ahmed A. Abd Elkhalek,

The Department of Neurosurgery, Faculty of Medicine,

Cairo University injuries, causing significant morbidity and mortality, causes of depressed skull fractures are blunt head trauma due to either road traffic accidents, assault or falling from a height venous sinus injury occur in $10 \%$ of cases of depressed fracture [5]

Because of the high risk of surgery of compound depressed fracture overlying sinuses, surgery should be selected only for cases with mass effect, with compression of the venous sinus by fracture or hematoma and for cases with deep contamination [7].

Venous sinus thrombosis is a rare form of venous thromboembolism, account for 0.5 to $3 \%$ of all types of stroke, 3-4 per 1,000,000 adult, 7 per $1,000,000$ in children, male to female ratio is $1: 3$ due to pregnancy, puerperium and oral contraceptive pills, risk factors are either inherited as homocysteinemia or factor V leiden homozygous mutation, or acquired as brain tumors, head trauma and CNS infections [14].

The pathogenesis of venous sinus thrombosis in head injury is not exactly known but many theories present like injury to endothelial lining, extension of thrombus from injured emissary vein, compression of the sinuses by intracranial edema, in addition in depressed fracture the fractured bone may press against or invade the brain which together with associated intracranial hematoma are the risk factors of sinus thrombosis [2].

Symptoms and signs of venous sinus thrombosis are headache (the most presenting symptom), seizures, hemiparesis and hemisensory affection, impairment of level of consciousness or pailledema [3].

Diagnosis of venous sinus thrombosis is through CT scan: in $40 \%$ generalized or localized hyperdenisity areas indicate hemorrhagic infarctions, 
string sign, empty delta sign (opacification of collateral veins in the wall of the superior sagittal sinus after contrast injection), CT may be normal in 10 to $20 \%$ of cases with venous sinus thrombosis [22].

MRI with MRV replaced the old invasive subtraction angiography, it can also provide better visualization of venous infarction, hemorrhage and brain parenchymal abnormalities. CT venography can be a rapid and reliable tool for detecting cerebral venous sinus thrombosis [22].

Anticoagulation therapy is the main line of treatment for patients with cerebral venous sinus thrombosis, both Unfractionated Heparin (UFH) or Low Molecular Weight Heparin (LMWH) can be used during the acute phase then oral anticoagulants are continued for a period from 3 to 12 months and most patients have a good prognosis after anticoagulation therapy [4] .

\section{Aim of work:}

In this research we will evaluate the incidence and management of venous sinus thrombosis following repair of cases of traumatic compound depressed skull fractures overlying venous sinuses.

\section{Patients and Methods}

Retrospective study of 40 cases of compound depressed fractures overlying dural venous sinuses, operated in the period between May 2015 to May 2016 in Neurosurgery Department Trauma Casualty Unit, Cairo University.

Inclusion criteria are age from 5 to 65 years and Glasgow coma scale from 8 to 15 and exclusion criteria are age blow 5 years or above 65 years, Glasgow coma scale less than 8 or bleeding tendency.

All patents with the inclusion criteria had informed written consent, full history taking including age, gender, profession, mode and time of injury, loss of consciousness, seizures, vomiting, nasal and ear bleed, site and type of fracture were documented, general examination and detailed neurological examination was done, pre-operative GCS was documented and CT scan of the brain with a bone window was done for all patient before surgery, all cases were given prophylactic antibiotics and anticonvulsant pre-operatively, and four units of blood was reserved for all patients.

Surgery was done to relieve sinus compression or to evacuate intracranial hemorrhage and reduce mass effect.
Post-operative GCS was measured, any postoperative complications like wound infection, CSF leak and any neurological deficit were documented.

All cases had CT brain with a bone window 24 hours post-operatively to demonstrate elevation of the depressed fracture, evacuation of the hematoma and to check for any signs of sinus thrombosis and MRV was done for all cases 48 hours postoperatively.

\section{Results}

In our study of 40 patients, 30 of them were males and 10 were females with male to female ratio 3: 1, with age ranging from 10 to 60 years with a mean age of 15.6 years.

Road traffic accident was the most common etiology in 16 cases, followed by fall in 11 cases, assault in 8 cases and object falling on the head in 5 cases.

A 40 cases of compound depressed fracture overlying sinuses were operated upon, 36 cases (90\%) involving superior sagittal sinus, 22 cases involving the anterior third (55\%), 10 cases involving the middle third (25\%), 4 cases involving the posterior third (10\%), and 4 cases overlying the transverse and sigmoid sinuses (10\%) Chart (1).

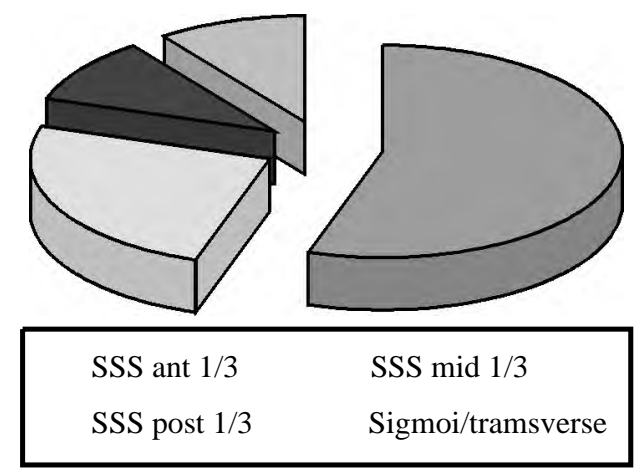

Fig. (1): Sinuses affected.

The GCS was $14-15$ in 27 patients $(67.5 \%)$, 9 13 in 11 patients $(27.5 \%)$ and $8-9$ in 2 patients (5\%).

In 22 cases (55\%) the bleeding was controlled by direct gelfoam compression, 10 cases $(25 \%)$ the bleeding was controlled by direct stitching of the dural tear followed by gelfoam compression, 6 cases $(15 \%)$ the bleeding was controlled by pericranium duroplasty, 2 cases (5\%) bleeding was controlled by free muscle duroplasty.

In our study 5 patients $(12.5 \%)$ had intraoperative bleeding and needed blood transfusion, 
two patients $(5 \%)$ developed wound infection which was treated with antibiotic, two patients $(5 \%)$ had neurological deficit.

All cases had a 24 hours post-operative CT, which showed elevation of the depressed fracture and evacuation of hematoma if present.

All cases had 48 hours post-operative MRV, two cases $(5 \%)$ developed complete obstruction of the venous sinus, the 2 cases which operated by pericranium duroplasty and were females, and one of them developed benign intracranial hypertension Chart (2).

The two cases with venous sinus thrombosis were directly treated with both supportive treatment as hydration, anticonvulsants, control of intracranial pressure and anticoagulation therapy.

The anticoagulation therapy we used was low molecular weight heparin LMWH (180U/kg/24 using two subcutaneous injection daily during the acute phase followed by oral anticoagulants for 3 to 6 months.
The patient with benign intracranial hypertension was treated conservatively with acetazolamide, steroids and repeated lumbar puncture.

Both patients showed improvement of condition after treatment.

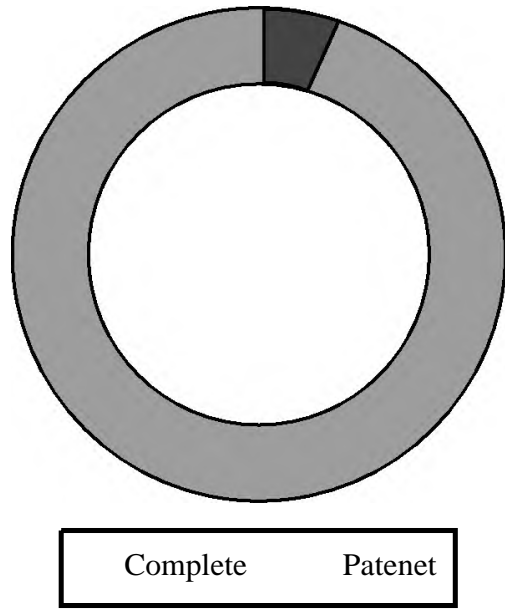

Fig. (2): Sinus obstruction.
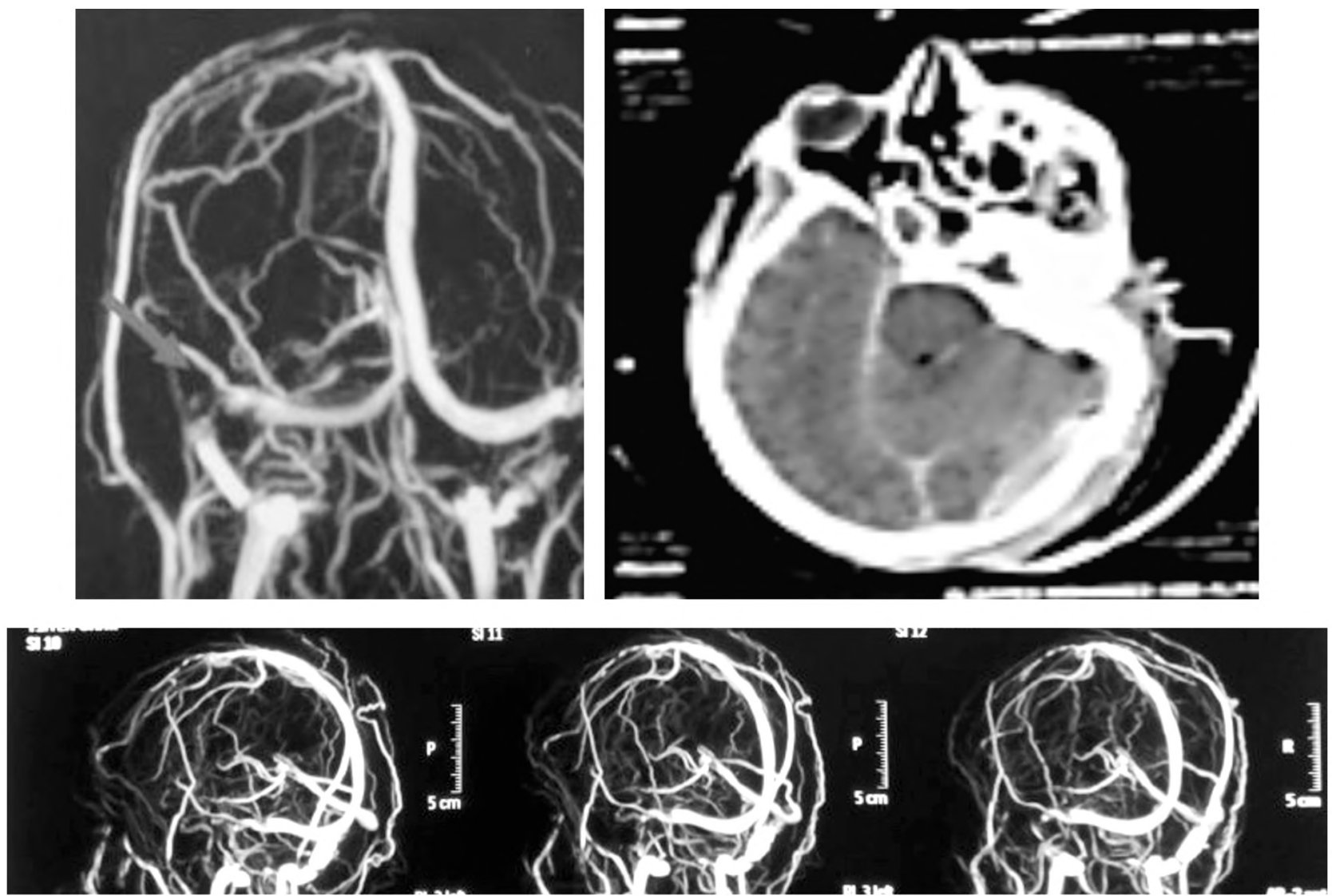

Fig. (3): The patient had left sided posterior parietal compound depressed fracture with bleeding from transverse sigmoid junction with MRV showing left sigmoid sinus stenosis. 


\section{Discussion}

Elevating depressed skull fractures overlying venous sinuses is considered hazardous due to risk of massive bleeding, so surgery should be selected only for cases with mass effect with compression of the venous sinus by fracture or hematoma to avoid fatal brain swelling and venous infarction and for cases with deep contamination.

Following head injury, skull fractures or intracranial hematomas can cause thrombosis either by direct compression of the sinus [19] or by damaging endothelial lining of the sinus wall which will be followed by activation of the coagulation system resulting in sinus occlusion [2]. Uncommonly, sinus thrombosis can occur after mild closed head injury with suture diastasis [16]. Early detection is important as early management with anticoagulation of this potentially treatable condition will result in good outcome, and thrombi in the sinuses frequently recanalize with time due to fibrinolysis [12]

Follow-up MRV should be the main diagnostic tool for those cases especially if the patient starting manifestations of increased intra cranial pressure or follow-up CT showed evidence of venous infarction in the form of hyperdense petechial hemorrhages and hypodense edema may be seen in the cortical grey matter and sub cortical white matter due to sinus obstruction [13].

LeFeuvre et al., [10] and Miller and Jennett [11] reported that the incidences of severe hemorrhagic complications in patients undergoing operative treatment for depressed skull fractures over a venous sinus are $23 \%$ and 20\%. Miller and Jennett [11] also reported an incidence of $11.5 \%$ in cases with simultaneous penetration of a venous sinus.

In our study 30 cases were males with $10 \mathrm{fe}$ males with a male to female ratio of 3:1 similarly to other studies reported more incidence of trauma in males. e.g. Ozer FD et al., [13] and Larking et al., [9] found that $61.9 \%$ of people with TBI were males, also Andersoon et al., [1] concluded that TBI in Sweden males had 1.46 higher rate than females. In our study we found that $85 \%$ of patients were in this age group (15-45 years), similarly Gan et al., [8] concluded that the incidence of TBI peak in the younger patients aged $20-40$ years.

In this study the main cause of injury was road traffic accident followed by fall from hight but with no significant difference in mortality and disability similarily to C. Woertgen et al., [23]
$90 \%$ of cases were involving the superior sagittal sinus with $10 \%$ involving tansverse and sigmoid sinuses, 22 cases involving the anterior third (55\%), 10 cases involving the middle third (25\%), 4 cases involving the posterior third (10\%), and 4 cases overlying the transverse and sigmoid sinuses other studies reported that SSS is the most injured sinus and the central part is the most affected part e.g: (Ozer FD et al., [13], Taghyan et al., [21] and Lefeuvre D et al., [10].

Sanjay et al., [14] reported that the anterior part of superior sagittal sinus is the most affected part $(80 \%)$ and the middle part was (20\%) match with this study Sanjay et al., [15] reported rarity of blood loss in their study.

Similarily to our study as 5 cases only need blood transfusion (500-1litre) and most of the patient in their study bleeding controlled by direct gelfoam compression for few minutes.

In 22 cases $(55 \%)$ the bleeding was controlled by direct gelfoam compression, 10 cases $(25 \%)$ the bleeding was controlled by direct stitching of the dural tear followed by gelfoam compression, 6 cases $(15 \%)$ the bleeding was controlled by pericranium duroplasty, 2 cases (5\%) bleeding was controlled by free muscle duroplasty, in the study of Ozer FD et al., [10] blood loss occurred intra operatively could be controlled by digital pressure with gel foam or with a free muscle flap.

Two patients (5\%) developed wound infection which was treated with antibiotic, two patients (5\%) had neurological deficit one with left lower limb weaknees and the other with right foot drop.

In our study there was no mortality.

Two cases were detected by MRV to have sinus thrombosis (5\%) involving tansverse and sigmoid sinus one was female in the childbearing period and the other was male with history of deep venous thrombosis, the female patient developed benign intracranial hypertension.

Ochagavia announced that the incidence of DST was $4 \%$ after penetrating head trauma [12]

Stiefel reported that he found DSTs with an incidence of $6.8 \%$ in the pediatric age group [18].

Medical treatment was given in the form of hydration, anticonvulsants, mannitol, acetazolamide and anticoagulation therapy (LMWH in our study) was the main line of treatment, other anticoagulants as heparin, urokinase or tissue plasminogen activator and it should be given carefully 
with close observation for fear of development of new bleeding.

Venous sinus thrombosis is considered a serious condition which can lead to progressive neurological complications or death if not urgently or properly treated [6].

Studies following recanalization of venous sinuses have shown that it may be incomplete in some cases [7,17]. Stolz et al., have presented a prospective study, in which significant functional improvement appeared about $89 \%$ in 12-month follow-up period; on the other hand, the recanalization rate was determined to be about $60 \%$ [20] Published papers of DST cases following closed head injury showed a high recanalization rate $[14,24]$

Furthermore, recurrence of DST is estimated to occur in approximately $12 \%$ and the patients also have an increased risk (14\%) of deep venous thrombosis. Because of these reasons, wee see that anticoagulation should be continued after discharge.

\section{Conclusion:}

Depressed skull fracture overlying cerebral venous sinus is associated with low risk of venous sinus thrombosis, every patient should have MRI venography, the prognosis of these patients is favorable if they have early diagnosis and management.

\section{References}

1- ANDERSSON E., H. BJOORKLUND, R. EMANUELSON and STALHAMMAR D.: Epidemiology of traumatic brain injury: A population based study in western Sweden, original articles, Acta Neurological Scandinavica, April, 71: 124-33, 2003.

2- DALGIC A., SECER M., ERGUNGER F., et al.: Dural sinus thrombosis following head injuries.report of two cases and review of the literature.turk Neurosurg, 18: 70: 77, 2008.

3- De BRUIJN S.F., STAM J. and KAPELLE L.J.: Thunderclap headache as first symptom of cerebral venous sinus thrombosis. CVST Study Group. Lancet, 348: 1623-5, 1996.

4- De BRUIJN S.F. and STAM J.: Randomized, placebocontrolled trial of anticoagulant treatment with lowmolecular-weight heparin for cerebral sinus thrombosis Stroke, 30: 484-8 infections, 1999.

5- DEVASAGAYAM S., WYATT B., LEYDEN J. and KLEINIG T.: Cerebral venous sinus thrombosis incidence is higher than previously thought: A retrospective population-based study. Stroke, 47: 2180-2, 10.1161/ STROKEAHA.116.013617, 2016.

6- DOBBS T.D., et al.: Cerebral venous sinus thrombosis complicating traumatic head injury. J. Clin. Neurosci., 19 (7): p. 1058-9, 2012.
7- FERRO J.M., CANHAO P., STAM J., BOUSSER M.G. and BARINAGARREMENTERIA F.: ISCVT Investigators Prognosis of cerebral vein and dural sinus thrombosis: Results of the International Study on Cerebral Vein and Dural Sinus Thrombosis. Stroke, 35: 664-70, 2004.

8- GAN B.K., LIM J.H.G. and NG I.H.B.: Outcome of moderate and severe TBI amongst the elderly in Singapore. Ann. Acad. Med. Singapore, January, 33: 36-7, 2004.

9- LARKING P.: Traumatic Brain Injury. Analysis of data Wellington, ACC, 2004

10- LeFEUVRE D., TAYLOR A. and PETER J.C.: Compound depressed skull fractures involving a venous sinus. Surg. Neurol., 62: 121-5; discussion 125-6, 2004.

11- MILLER J.D. and JENNETT W.B.: Complications of depressed skull fracture. Lancet, 2: 991-5, 1968.

12- OCHAGAVIA A.R., BOQUE M.C., TORRE C., ALONSO S. and SIRVENT J.J.: Dural venous sinus thrombosis due to cranial trauma. Lancet, 347: 1564, 1996.

13- OZER F.D., YURT A., SUCU H.K. and TEKTAS S.: Depressed fractures over cranial venous sinus. J. Emerg. Med., Back to cited text no 3, 29: 137-9, 2005.

14- ROACH E.S., GOLOMB M.R., ADAMS R., et al.: American Heart Association Stroke Council; Council on Cardiovascular Disease in the Young. Management of stroke in infants and children. Stroke, 39: 2644-91, 2008.

15- SANJAY K. BEHERA, SATYA BHUSAN SENAPATI and SUDHANSU SEKHAR: Management of superior sagittal sinus injury encountered in traumatic head injury patients. Analysis of 15 cases: Mishra, Vol. 10 Issue 1 Page 17-20, 2015.

16- SATOH H., KUMANO K., OGAMI R., NISHI T., et al.: Sigmoid sinus thrombosis after mild closed head injury in an infant: Diagnostic by magnetic resonance imaging in tha acute phase-case report. Neurol. Med. Chir. (Tokyo), 40: 361-5, 2004.

17- SINDOU M.P. and ALVERNIA J.E.: Results of attempted radical tumor removal and venous repair in 100 consecutive meningiomas involving the major dural sinuses. J. Neurosurg., 105: 514e525 S Kalayanaraman (1996) Scalp and Skull Injuries. In: Textbook of Neurosurgery. (Ed.) Churchill Livingstone New Delhi, 289, 2006.

18- STIEFEL D., EICH G. and SACHER P.: Posttraumatic dural sinus thrombosis in children. Eur. J. Pediatr. Surg., 10: 41-4, 2000

19- STOLZ E., TRITTMACHER S., RAHIMI A. GERRIETS T., ROTTGER C., SIEKMANN R. and KAPS M.: Influence of recanalization on outcome in dural sinus thrombosis: A prospective study. Stroke, 35: 544-7, 2004.

20- TAHA J.M., CRONE K.R., BERGER T.S., BECKET W.W. and PRENGER E.C.: Sigmoid sinus thrombosis after closed head injury in children Neurosurgery, 32: 541-5, 1993.

21- TAGHYAN A.H. MOUSA and RADWAN ELNOUPY: Compound depressed skull fractures overlying dural venous sinuses. Pan. Arab Journal of Neurosurgery, volume, 2010. 
22- VOGL T.J., BERGMAN C., VHLRINGER A., EINHAUPL K.M., LISSNER J. and FELIX R.: Dural sinus thrombosis: Value of venous MRA for diagnosis and follow-up. A.J.R. Am. J. Roentgenol., 162: 1191-8, 1994.

23- WOERTGEN C., ROTHOERL R.D., METZ C. and
BRAWANSKI A.: Head injury outcome prediction in the Emergency Department, 37 (12): 1098-108, 2006.

24- YUEN H.W., GAN B.K., SEOW W.T. and TAN H.K.: Dural sinus thrombosis after minor head injury in a child. Ann. Acad. Med. Singapore, 34: 639-41, 2005.

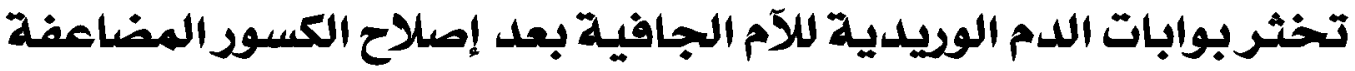

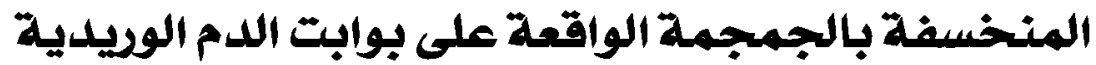

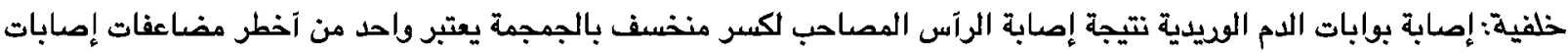
المخ، لآنه قد يحدث مضاعفات آثاء الإصلاح تقؤى إلى نزيف مميت آو بعد العملية تؤدى إلى تخسر بوابان الدم الوريدية للآم الجافية.

الهدف من الدراسة: فى ثلك الدراسة سوف نددد نسبة حدوث وطريقة علاج تخسر بوابات الدم الويدية للآم الجافية بعد إصلاح كسر مضاعف منضسف بالجمجمة يقع على بوابات الدم الدوالية لوفيدية للآم الجافية.

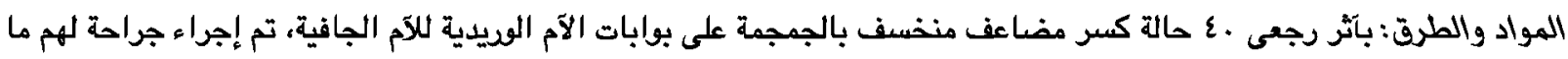

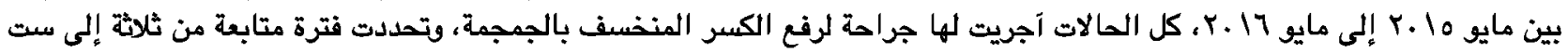
شهنو.

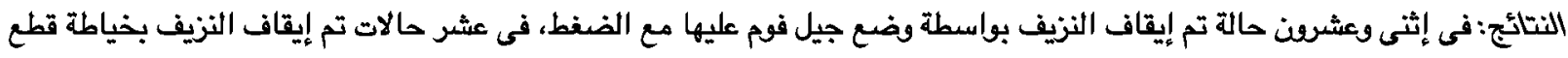

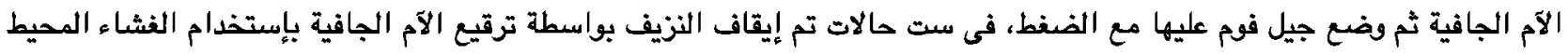

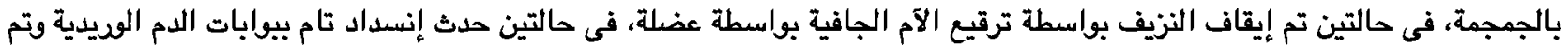

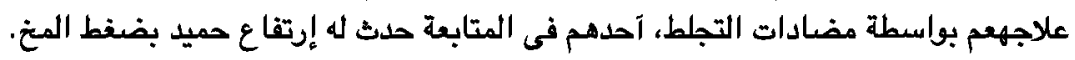

الخلاصة: تخثر بوابات الدم الويدية للآم الجافية غير محتمل الدوثث بعد إصلاح الكسود المضاعفة المنخسفة بالجمجمة التى تقع على

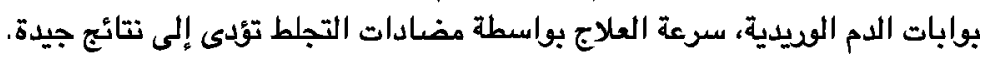

